\title{
Elucidating the atomic structures of different sources of fly ash using X-ray and neutron PDF analysis
}

\author{
Maria Elia Natali $^{1 *}$, Claire E. White ${ }^{2}$, Maria Chiara Bignozzi $^{3}$
}

${ }^{1 *}$ Corresponding author: Dipartimento di Ingegneria Civile, Chimica, Ambientale e dei Materiali

Università di Bologna, Via Terracini 28, 40131 Bologna, Italy, email: mariaelia.natali2@unibo.it

${ }^{2}$ Department of Civil \& Environmental Engineering and Andlinger Center for Energy and the

Environment, Princeton University, Princeton, USA, email: whitece@ princeton.edu

${ }^{3}$ Dipartimento di Ingegneria Civile, Chimica, Ambientale e dei Materiali

Università di Bologna, Via Terracini 28, 40131 Bologna, Italy, email: maria.bignozzi@unibo.it

\section{Keywords}

Fly Ash, Amorphous Materials, X-ray Diffraction, Neutron Diffraction, Pair Distribution Function, Atomic structure.

\begin{abstract}
This paper presents the comparative results obtained from X-ray and neutron pair distribution function (PDF) analysis aimed at determining the variability in aluminosilicate glass chemistry in five types of class F fly ash (FA). Results have been discussed in light of the complementary information provided by the two methods in order to give a comprehensive overview of FA structure at the nanoscale. The analysis of short range correlations reveals that the bulk glassy structure of FA sources differing in chemical composition are relatively similar, but some specific distinctions in atomic structure are visible in those containing high levels of amorphous VIcoordinated aluminum (e.g., amorphous mullite/alumina), iron and/or carbon (with similar local bonding environment to graphite). The obtained experimental results fill a deficit in literature in the atomic structure and associated variability for class F FA, which is extensively used in several industrial applications including as raw material in alkali-activated cements.
\end{abstract}

\section{Introduction}

Over the last decade there has been a rapid increase in scientific research on alkali-activated materials (AAMs) and geopolymers [1,2]. This due to the pressing need to implement sustainable and zero-energy consuming technologies (including materials) in the construction industry, primarily via the promotion of partial/total substitution of ordinary Portland cement (OPC) with industrial by-products or waste materials. For the case of AAMs, amorphous aluminosilicates, 
which are by-products of industrial processes, are used as precursor materials, such as groundgranulated blast furnace slag (GGBS) and coal-derived fly ash (FA). Recent studies have also highlighted the potential for other types of precursors derived from waste streams such as coal gangue and red mud [3]. The term 'AAMs' includes any binder system derived from the reaction of a solid aluminosilicate-rich powder with an alkaline salt, such as sodium hydroxide and sodium silicate. Certain types of AAMs, such as those derived from GGBS, are also rich is calcium, and are known to form sodium-containing calcium-alumino-silicate-hydrate (C-(N)-A-S-H) gels [4]. For AAMs that have relatively low concentrations of calcium and high amounts of aluminum it is possible to define a subset known as geopolymers, for $\mathrm{SiO}_{2}+\mathrm{Al}_{2} \mathrm{O}_{3} \geq 80$ wt. \%, which include binders synthesized using class F FA, characterized by a sodium-alumino-silicate-hydrate (N-A-SH) gel $[5,6]$.

The ability to obtain a deep understanding of the intrinsic characteristics of the raw material (i.e., atomic structure and associated variability, nanoscale morphology, particle size distribution) is key for controlling the alkali-activation reaction, particularly for the non-process-controlled by-products (including GGBS and FA), which can have highly variable compositions and atomic structures, even for material derived from a single plant. Determining the structure of these industrial byproducts at nanoscale/atomistic level is necessary so that this information (such as variability in the atomic structure) can be linked to any differences in structural properties and reaction mechanisms measured during the alkali-activation reaction, together with the impact on the resulting mechanical properties. The challenge in characterizing the atomic structure of the precursor materials along with the chemical reactions and associated mechanisms occurring during alkali-activation is mainly due to the disordered nature of all phases throughout the course of the reaction process.

This investigation focuses on class F FA, which is an industrial by-product of coal power stations. Even though the worldwide production of class C/F FA is actually increasing and anticipated to reach approximately 2000 million tons in 2020, only $45 \%$ is valorized for different purposes including as a supplementary cementitious material (SCM), while the remaining $55 \%$ is disposed of in landfills [7]. The use of class F FA as an aluminosilicate precursor for geopolymerization has been studied extensively over the last few decades, with a large number of publications revealing the suitability of these binders as cement alternatives in the field of construction materials [8,9]. It has been shown that the intrinsic characteristics of the FA, particularly particle size distribution, morphology, amorphous fraction and oxide composition [6,10-16], the mix design, including type and dosage of activators [17,18], and reaction conditions (i.e., temperature, humidity, curing regime and duration) $[19,20]$ can influence the final properties of the geopolymeric product. Moreover, certain formulations of FA-based geopolymers have good thermal stability upon firing at 800-1200 ${ }^{\circ} \mathrm{C}$ [21], are resistant to acid attack and the alkali-silica reaction (ASR) [22] and assist in preventing corrosion of steel reinforcement $[23,24]$. In addition to the use of FA-based geopolymer binders in the construction sector, FA represents a promising material for a range of other applications such as soil amelioration, ceramics, catalysts, and in zeolite synthesis [25-27].

\subsection{Fly ash for geopolymerization: atomic structure characterization methods (crystalline and amorphous phases)}

Given the broad range of promising applications for FA, it is important to have a detailed understanding of the chemistry, physical attributes and associated variability in properties for this underutilized industrial by-product. The composition and properties of FA are linked to the physical and chemical properties of the coal rank combined with the attributes of the combustion process $[25,26]$. Furthermore, it is well accepted that chemical variability may also be found in FA sourced from the same coal power plant $[10,14]$. 
For the use of industry by-products in geopolymers, particle size distribution, chemical composition and crystalline structures/glassy phases of the precursor material are key factors that must be understood, as this information controls the precursor reactivity and solubility in an alkaline solution [10-16]. Particle size distribution, morphology and chemical composition, which are relatively easy to detect via traditional characterization methods (i.e., laser granulometry, optical microscopy, scanning electron microscopy-energy dispersive X-ray spectroscopy (SEM-EDS), inductively coupled plasma-optical emission spectrometry (ICP-OES), X-ray fluorescence (XRF)) reveals in most cases similar properties for different FA sources, even though these different sources are seen to result in geopolymeric products with vastly different performance characteristics $[13,15]$. Conversely, characterization and quantification of glassy phases and their relevant modification after geopolymerization, which is challenging due to the disordered nature of these phases at the atomic length scale, can lead to determination of crucial differences in the atomic structures. Magic-angle-spinning nuclear magnetic resonance (MAS NMR) performed on FA usually reveals resonances between -80 and $-108 \mathrm{ppm} \mathrm{[16],} \mathrm{which} \mathrm{are} \mathrm{associated} \mathrm{to} \mathrm{the} \mathrm{glassy}$ phases and poorly ordered crystalline structure, however this technique is mostly used to monitor the structural reorganization of the gel after geopolymerization. In fact, peak identification remains somewhat controversial in the literature, where a single resonance can be attributed to crystalline or disordered phases (albeit with possible differences in the full-width half-maximum of these peaks), and chemical shifts are influenced by the multiple possibilities that exist for bonding environments involving non-bridging oxygens [28]. Other limitations include the presence of overlapped peaks, where deconvolution is carried out using the assumption of Gaussian line shapes together with the minimum possible number of components (Gaussians) for an accurate description of the given spectrum [28].

Other quantitative methods used in the literature are devitrification [13,29] and the Arjuan's dissolution method $[16,30]$. The first consists of performing thermal treatment on the FA over a range of temperatures and residence times followed by analysis of the crystalline materials which formed during thermal treatment using X-ray diffractometry (XRD). Although this technique detects differences in terms of glass separation (i.e., the formation of glassy $\mathrm{SiO}_{2}$ or $\mathrm{Al}_{6} \mathrm{Si}_{2} \mathrm{O}_{13}$ ) [13] the crystallization temperature of some phases may coincide with the formation of small amounts of other phases so that an unambiguous separation is not obtainable. The dissolution method consists of dissolving glassy phases in $1 \% \mathrm{HF}$ acid (wt. \%) and subtracting the residual mass from the initial $[16,30]$, which clearly does not allow for identification of any qualitative information on the dissolved glassy composition. Other investigations include a synergy of XRD, SEM-EDS and multispectral image analysis (MISA) [11,12]; where individual images are mathematically linked to form a multispectral image suitable for detection and quantification of the individual phases. Even though the results from this method show promise in the detection of the various glassy components and are consistent with Rietveld quantitative X-ray diffraction analysis [31], they are based on a series of analytical assumptions and user-defined constraints, which can have an influence on the resulting images. Reciprocal space analysis (using X-ray or neutron scattering data) and subsequent Rietveld refinement [31] are excellent methods for identification and quantification of the crystalline phases in FA, and, through the use of XRF in combination with Rietveld analysis, quantitative information on the amorphous fraction in the FA can be obtained together with the average chemical composition of this amorphous component. However, the main limitation of these methods is the fact that they do not reveal any information on the local atomic structure of the amorphous component, since amorphous structural information is manifested as a relatively featureless diffuse peak in reciprocal space data [32].

\subsection{Atomic structural characterization of amorphous phases in FA: The PDF technique}


The aforementioned methods give a comprehensive quantitative/qualitative description of crystalline structure and microstructure of FA, however, the major limitation of these methods is the lack of information on the local atomic structure of the amorphous phases. This information is crucial as it is largely responsible for the reactivity of the FA during the alkali activation reaction, and therefore contributes to the physical properties of the resulting geopolymer binder. On the other hand, X-ray and neutron total scattering and subsequent pair distribution function (PDF) analysis is ideally suited for analyzing amorphous and nanocrystalline materials, since diffuse scattering arising from disordered phases gives rise to distinct atom-atom correlations in real space [33]. Analyses carried out using the PDF technique include the study of synthetic calcium-silicatehydrate (C-S-H) gels in conventional cement [34,35], and the analysis of the carbonation reaction in this gel [36]. The latter investigation (carbonation of C-S-H gel) revealed how the use of real space scattering data (PDFs) enabled for a more accurate determination of the various phases (crystalline and disordered) that are present throughout the carbonation reaction [36].

Previous investigations have centered on using PDF analysis to study the local atomic structure of metakaolin and metakaolin-based geopolymers, since this aluminosilicate precursor is often used as a model system for class F fly ash [37-42]. PDF data on metakaolin-based geopolymers have been obtained using X-ray and neutron PDF analysis, including in situ experiments on the geopolymerization reaction over an extended time period (up to 128 days) [40]. These investigations have revealed the role free silica in the activator plays in the geopolymerization reaction (in silicate-activated metakaolin pastes), including the influence on reaction kinetics and the resulting sodium aluminosilicate $(\mathrm{N}-\mathrm{A}-\mathrm{S}-\mathrm{H})$ gel. Silica promotes metakaolin dissolution at early stages of the reaction but is seen to reduce the rate of reaction at later stages compared to hydroxide-activated metakaolin pastes, likely due to the enhanced precipitation of the gel on the partially reacted particles, thus limiting further dissolution of the metakaolin particles [40]. PDF analyses of alkali-activated metakaolin-GGBS and GGBS pastes have highlighted the role of calcium in the evolution of nanostructure during the alkali-activation reaction. Specifically, for GGBS-based pastes more significant changes were observed in the local atomic structure of hydroxide-activated systems compared to silicate-activated over the initial $10 \mathrm{hrs}$ of formation [43]. An overview of the research centering on the nanostructural characterization of metakaolin-based geopolymers and alkali-activated GGBS pastes using synchrotron beam-line techniques is reported Provis et al. [33], while Meral et al. [39] analyzed a range of supplementary cementitious materials using PDF analysis including silica fume, class F FA and metakaolin. In the aforementioned paper only one type of class F FA was analyzed by X-ray PDF analysis and, prior to measurement, the sample was processed to isolate the glassy phase by density difference of the constituents [44].

The purpose of this investigation is to determine the structural variability in aluminosilicate glass chemistry for different sources of class F FA, obtained from several coal power stations around the world. Five types of unprocessed FA have been analyzed using room temperature X-ray and neutron total scattering analysis. Crystalline phases have been identified and their scattering contributions subtracted from the PDF data in order to isolate FA glassy components. Results have been discussed in the light of the complementary information given by the two methods (X-rays and neutrons) in order to give a comprehensive overview of the bulk local atomic structures of these FA samples, with this new information giving important clues on the parameters controlling reactivity of this aluminosilicate precursor.

\section{Experimental}

\subsection{Raw materials}

Five types of class F FA sourced from different coal power stations around the world have been 
analyzed in this study. Italian and Australian FA (designated IFA and AFA) were sourced from Enel Produzione S.p.A. Torrevaldaliga Nord power station located in Italy (Civitavecchia, Rome) and Collie power station in Western Australia, Australia, respectively. A detailed characterization of these two sources of FA is reported in literature [6]. German FA (EFA-Füller ${ }^{\circledR}$ HP, here designated GFA) was sourced from Heyden power plant located in Petershagen (Germany). American FA (AFA) was sourced by PSEG Mercer power station located in Hamilton, NJ (USA), while a high carbon-content FA (HCFA) was sourced by Headwater Resources Bryton Point power station located in Somerset, MA (USA). An overview of the principal oxide composition for the investigated samples is reported in Tab. 1 and Tab. 2.

\section{$2.2 X$-ray and neutron data acquisition and analysis}

Synchrotron X-ray total scattering data were collected at the 11-ID-B beamline at the Advanced Photon Source (APS), Argonne National Laboratory (ANL). Powder samples were loaded into polyimide capillaries and measured in transmission mode at ambient laboratory temperature using a Perkin Elmer amorphous silicon image plate detector [45] located at $172.8 \mathrm{~mm}$ from the sample. Data for an empty capillary and a Ni powder standard were also collected. A wavelength of 0.2114 $\AA$ was used $(58.65 \mathrm{keV})$ and the measurement time was 20 min total with $0.1 \mathrm{~s}$ for each exposure. The program Fit2D [46] was used to calibrate the sample to detector distance and detector alignment using data from a $\mathrm{CeO}_{2}$ powder standard. The normalized total scattering patterns, $S(Q)$, and subsequent PDFs were produced using PDFgetX2 [47]. PDFs, $G(r)$, were calculated via a sine Fourier transformation of the total scattering data utilizing a $Q_{\max }$ of $23.5 \AA^{-1}$. The Ni dataset was fit in PDFgui [48] between 1 and $50 \AA$ to obtain the instrument parameters, $Q_{\text {damp }}$ and $Q_{\text {broad }}\left(Q_{\text {damp }}\right.$ of $0.037 \AA^{-1}$ and $Q_{\text {broad }}$ of $0.030 \AA^{-1}$ ). The PDFs of the amorphous phases existing in the samples were obtained by subtracting contributes from the crystalline phases of quartz, mullite, and maghemite or magnetite by the use of PDFgui [48] and refinement of the scale factor, atomic displacement $\left(u_{i}\right)$ and lattice parameters $(a, b$ and $c$ ) over the $r$-range $0.01-49.99 \AA$.

Neutron data were collected at the Nanoscale-Ordered Materials Diffractometer (NOMAD) beamline located at the Spallation Neutron Source (SNS), Oak Ridge National Laboratory (ORNL). Powder samples were loaded into quartz capillaries and each data set was collected for 2 hours total run time, in $30 \mathrm{~min}$ segments, at ambient laboratory temperature. An empty capillary was also measured. To produce each total scattering function and associated PDF, the measured scattered intensities were normalized by scattering from a vanadium rod and subjected to a background subtraction from the empty capillary using the IDL software developed for the NOMAD instrument [49]. As was the case for X-rays, the neutron PDFs were obtained via a sine Fourier transform of the total scattering function, $S(Q)$, using a $Q_{\max }$ of $28 \AA^{-1}$ and $Q_{\min }$ of $0.5 \AA^{-1}$. The instrument parameters for NOMAD were $Q_{\text {damp }}$ and $Q_{\text {broad }}$ of $0.0176 \AA^{-1}$ and $0.0192 \AA^{-1}$, respectively.

For both X-ray and neutron datasets the Fourier transform of the total scattering was obtained as follows:

$G(r)=\frac{2}{\pi} \int_{Q=Q_{\min }}^{Q=Q_{\max }} Q[S(Q)-1] \sin (Q r) d Q$

where $Q$ is the momentum transfer defined as:

$Q=\frac{4 \pi \sin \theta}{\lambda}$ 
Reciprocal space analysis was carried out on the X-ray and neutron data, where the crystalline phases were identified using Diffrac.EVA software version 3.1 together with the PDF-2/Release 2013 RDB database.

$1 \mathrm{~mm}$ diameter polyimide capillaries (for X-ray measurements) and $2 \mathrm{~mm}$ diameter quartz capillaries (for neutrons) were used in this investigation. The larger diameter capillaries for neutrons were necessary due to the weaker scattering when using this radiation source. Measurement times were optimized to obtain similar signal/noise ratios for X-rays and neutrons.

\section{Results and discussion}

\subsection{Reciprocal space $X$-ray and neutron data}

A comparison of the FA reciprocal space diffraction patterns, with the major crystalline phases identified, is presented in Fig. 1, where both X-ray (Fig. 1a) and neutron data (Fig. 1b) are reported. All the FA samples exhibit the typical amorphous broad hump between a $Q$ value of 1 and $2.5 \AA^{-1}$, which corresponds to a $2 \theta$ region of $15^{\circ}$ to $35^{\circ}$ for $\mathrm{Cu}-\mathrm{K} \alpha$ radiation. In addition to the amorphous component there are a number of crystalline phases present including quartz $\left(\mathrm{SiO}_{2}\right.$, PDF \#00-0010649), mullite $\left(\mathrm{Al}_{6} \mathrm{SiO}_{2} \mathrm{O}_{13}\right.$ PDF \#00-001-0613) and iron oxides such as maghemite $\left(\mathrm{Fe}_{2} \mathrm{O}_{3}, \mathrm{PDF}\right.$ \#00-013-0458) or magnetite $\left(\mathrm{Fe}^{2+} \mathrm{Fe}^{3+}{ }_{2} \mathrm{O}_{4} \mathrm{PDF} \# 00-019-0629\right)$ and, particularly in case of AFA and AMFA, hematite $\left(\mathrm{Fe}_{2} \mathrm{O}_{3}\right.$, PDF \#00-002-0915). Due to similarities in the Bragg scattering for maghemite and magnetite, it is difficult to distinguish between these two phases using reciprocal space analysis. In the proceeding sections it will be shown that by using PDF analysis it is possible to distinguish between these two iron oxide phases.

\subsection{X-ray pair distribution functions}

To isolate the amorphous glassy contributions in the X-ray PDFs, crystalline phases have been subtracted from the experimental data. The crystalline atomic structures chosen for the subtraction process were the one proposed by Gualtieri for the structure of quartz [50] (ICSD \#90145), by Durovič for mullite [51] (ICSD \#237026), by Shmakov et al. for maghemite [52] (ICSD \#79196) and by Iizumi et al. for magnetite [53] (ICSD \#35000). Concerning the iron oxide crystalline phases, maghemite was chosen for all FA samples except for AFA, where the magnetite structure was used for refinement since it led to better agreement with the experimental data (i.e., lower value for the goodness of the fit, $R_{w}$, as defined in PDFgui [48]). Given the low concentration of hematite in the samples together with the relatively low $Q$ space resolution (and therefore resolution in the PDFs), this phase was not chosen for the refinement, as preliminary analysis revealed that including this phase did not lead to a significant reduction in $R_{w}$. A spherical form factor (spherical particle diameter, spdiameter, as defined in PDFgui [48]) for both the mullite and maghemite/magnetite phases led to a reduced $R_{w}$ value for all X-ray FA data, indicating the possible presence of nanocrystalline mullite and maghemite/magnetite in these samples (with a spherical particle diameter of $\sim 70 \AA$ ). Scale factors for the crystalline phases, as determined using PDFgui [48], are reported in Tab. 3 while peaks positions for the nearest-neighbor atom-atom correlations before and after crystalline subtraction are reported in the Supplementary Material (Tab. S1).

The results of the real space analysis are provided in Figs. 2 and 3. All the datasets have been normalized to the total amount of silicon and aluminum ( $\mathrm{Si}+\mathrm{Al}$ in molar \%), as determined from the total molar content $(\%)$ of the major elements present in each FA composition ( $\mathrm{Si}, \mathrm{Al}, \mathrm{Fe}$ and $\mathrm{Ca}$ ) given in Tab. 2. The PDF atom-atom correlation that provides a direct measure of the total $\mathrm{Si}+\mathrm{Al}$ content in the FA is the T-O correlation (tetrahedral $\mathrm{Si}$ and $\mathrm{Al}$ ) located at $\sim 1.62 \AA$, as visible in Figs. $2 \mathrm{~b}$ and $3 \mathrm{~b}$. This normalization method assumes that all aluminum exists as IV-coordinated in 
the samples. This assumption is based on previous work investigating the coordination state of aluminum in aluminosilicate glassy phases [39,54,55], however, the coordination of aluminum in mullite, as well in the other crystalline phases such as sillimanite and kyanite, is known to also contain VI-coordinated sites [51,56]. Nevertheless, given the relative low percentages of these crystalline phases in comparison to the dominant glassy component, together with the fact that some of the aluminum in the crystalline phases exists as IV-coordinated, this normalization process is a good approximation for the behavior of the scattering data.

Fig. 2 displays the X-ray PDFs of the FA samples measured in this study after Fourier transformation of the total scattering patterns, while Fig. 3 shows the glassy aluminosilicate phases in the FA (crystalline phases have been subtracted). As is visible from the long-range information (Figs. $2 \mathrm{a}$ and $3 \mathrm{a}$, above $\sim 10 \AA$ ) the intensity of the atom-atom correlations decreases relatively rapidly with increasing atom-atom distance $(r)$, with the FA samples losing a significant amount of atomic ordering above $5 \AA$. This indicates a mostly amorphous structure for all the considered FA, especially after subtraction of the crystalline phases (Fig. 3). The short-range information $(1 \leq r \leq 5$ $\AA$ ) is representative of the local bonding environments present in these amorphous systems (Figs. $2 b$ and $3 b$ ). It is clear from Figs. $2 b$ and $3 b$ that the majority of the disagreement in local atomic ordering in the samples is attributed to the presence of crystalline phases, and that after removal of these phases there is generally good agreement in the local atomic ordering of the glassy components, with no strong atom-atom correlations above $3.5 \AA$. The nearest-neighbor atom-atom correlation is present at $\sim 1.62 \AA$ in Fig. $3 \mathrm{~b}$, which is attributed to the tetrahedral silicon and aluminum atoms (T-O). Previous literature on aluminosilicate glasses (which consist of mainly tetrahedrally-coordinated silicon and aluminum) reveals that as the aluminum content increases, the average T-O distance increases ( $\mathrm{Si}-\mathrm{O} \sim 1.60 \AA$ and $\mathrm{Al}-\mathrm{O} \sim 1.75 \AA$ ) [57]. Hence, analysis of the T-O correlation in the FA glassy components in Fig. 3b reveals the presence of an aluminosilicate tetrahedral network similar to the one found by Meral et al. [39]. It is clear from Fig. $3 b$ that the majority of the FA samples contain similar T-O correlations, however, the AFA sample contains an aluminosilicate glassy network with a slightly lower percentage of alumina, as seen by a shift in the T-O peak to lower $r$ values.

The peak at $\sim 1.95 \AA$ in Fig. $2 \mathrm{~b}$ can be attributed to an Al-O correlation (in case of VI-coordinated alumina present in mullite structure [51]) and/or to $\mathrm{Fe}-\mathrm{O}$ for $\mathrm{Fe}^{3+}$ with coordination number of $\mathrm{V}$ [58-60] or even to a mix of Fe-O correlations as reported by Weigel et al. [61]. Although crystalline mullite has been removed from the PDF data in Fig. 3b, it is possible that VI-coordinated Al is still present in the glassy phases as amorphous mullite [13] or amorphous alumina and the Al-O distance of $1.95 \AA$ from Fig. $3 b$ is in agreement with the mullite data proposed by Fisher [62]. As will become evident during the discussion of the neutron data (Section 3.3), the iron-containing correlations are present at different $r$ values compared to the peaks visible in the X-ray data in Figs. $2 \mathrm{~b}$ and $3 \mathrm{~b}$. Therefore, the peaks at $1.95 \AA$ and $3.42 \AA$ in the X-ray PDF data are attributed to Al-O and Al-Al, respectively, for VI-coordinated aluminum existing in an amorphous alumina phase such as amorphous mullite. The atom-atom correlation at $\sim 2.62 \AA$ is attributed to O-O [39], while the correlation at $\sim 3.08 \AA$ is related to T-T environments (i.e., Si-Si and $\mathrm{Si}-\mathrm{Al}$, with Al-Al correlations absent due to Löwenstein's rule for tetrahedral aluminum) $[39,63]$. Subtle differences are seen in Fig. $3 b$ for the T-T correlation according to the FA source. There is a slight shift to higher T-T correlations for IFA, which correlates with a higher Al content in the bulk chemical composition for this FA sample (Tab. 2). Therefore, this FA sample contains a higher amount of Si-O-Al linkages compared to the other samples. An evident correlation at $\sim 4.15 \AA$ is visible in Fig. $2 b$ which mainly disappears after subtraction of the crystalline phases and is attributed to either quartz or mullite.

As mentioned in the literature, the glassy spherical particles that constitute FA are known to be heterogeneous in terms of chemical composition [12-16]. Therefore, the reactivity of individual FA 
particles in a source of FA can be significantly different, with some particles dissolving during the alkali-activated reaction, while others remain completely intact [64]. Therefore, there will be a range of glassy structures in the FA samples studied in this investigation, with the PDF data providing the average glassy structure of each FA source (i.e., the average amorphous structure after subtraction of the crystalline phases, as shown in Fig. 3b). Ideally the distribution of amorphous structures throughout the FA sample would be accessible, and with recent developments in micron-resolved PDF analysis [65], this analysis approach may become readily accessible within the next couple of years. Nevertheless, the PDF data presented in the current investigation has shed light on the variability in the average glassy structure for different sources of class F FA. The X-ray PDF results shown in Fig. 3 reveal that there is relatively little difference in atomic ordering among the different types of FA, apart from those FA samples containing high levels of amorphous mullite/alumina (as is the case for AFA).

\subsection{Neutron pair distribution functions}

Neutron PDFs have been obtained to provide complementary data to the X-ray PDFs, particularly since iron, carbon and oxygen atoms have relatively large coherent neutron scattering lengths compared to silicon and aluminum. Given the difference in the neutron scattering lengths between silicon and aluminum, a different normalization process has been used compared to the X-ray data, specifically by taking into consideration the different coherent neutron scattering length densities (b) of the major atoms ( $\mathrm{Si}, \mathrm{Al}, \mathrm{Ca}$ and $\mathrm{Fe}$ ). All datasets have been normalized to the T-O correlation considering the amount of silicon and aluminum in the sample weighted by the scattering strength of each element, as depicted in eq. 3 .

$\operatorname{Si}(\operatorname{molar} \%) \times b_{S i}+A l(\operatorname{molar} \%) \times b_{A l}$

The neutron PDFs are shown in Fig. 4. As for the X-ray data, a crystalline subtraction process has been performed on each dataset, with the results given in Fig. 5. Scale factors for the crystalline phases for neutrons, as determined using PDFgui [48], are reported in Tab. 3. It is apparent that there are differences in the scale factors according to the type of radiation used (X-rays versus neutrons), especially for mullite, which is attributed to the relatively weak scattering of neutrons from aluminum atoms. Such discrepancies in scale factors according to the type of radiation used have been previously reported in the literature [66]. Peaks positions for the nearest-neighbor atomatom correlations before and after crystalline subtraction are reported in Supplementary Material (Tab. S2).

The neutron PDF data in Figs. 4a and 5a reveal the lack of long-range ordering above $\sim 10 \AA$, which confirms that the FA samples are predominately amorphous. The presence of strong scatterers (e.g., Fe and $\mathrm{C}$ ) in the neutron data is particularly evident for HCFA and AFA, where the PDF data show the most differences relative to the other samples. In fact, HCFA exhibits distinct atom-atom correlations at different $r$ values compared to the other FA samples, which is attributed to carbon-containing correlations. Furthermore, AFA contains specific peaks related to ironcontaining correlations due to the higher scattering strength of iron compared to aluminum for the case of neutrons $\left(b_{F e}=9.45 v s b_{A l}=3.44\right)$. The majority of peaks at low $r$ in Figs. $4 \mathrm{~b}$ and $5 \mathrm{~b}(1 \leq \mathrm{r} \leq$ $1.5 \AA$ ) are termination ripples as their position has been shown to shift with a change in the $Q_{\max }$ used to produce the PDF data. However, for HCFA an intense peak appears at $\sim 1.39 \AA$ which is attributed to the $\mathrm{C}-\mathrm{C}$ correlation found in a graphene sheet at $\sim 1.42 \AA$ [67]. This seems to be directly linked to the LOI content (i.e., $\mathrm{LOI}_{\mathrm{HCFA}}$ of $11.37 \mathrm{wt}$ \%, which is the highest among all the FA samples investigated here). The high carbon content in this type of FA seems to particularly affect its nanoscale structure (Fig. 5b), although no evidence of crystalline carbon phases was observed in the total scattering pattern (Fig. 1b). 
The local atomic ordering in the FA samples (Fig. 5b) reveals the presence of two distinguished peaks at $\sim 1.87 \AA$ and $\sim 2.08 \AA$, which were not evident in the X-ray data. The intensities of these two peaks follow the iron content (Tab. 1) and their $r$ values are in good agreement with the correlations found by Weigel et al. [61] for $\mathrm{Fe}-\mathrm{O}$ correlations in Fe-aluminosilicate glasses. According to the investigation by Weigel et al., the shorter distance can be assigned to IVcoordinated $\mathrm{Fe}^{3+}$ and the second either to $\mathrm{V}$-coordinated $\mathrm{Fe}^{3+}$ either to $\mathrm{V}$-coordinated $\mathrm{Fe}^{2+}$. Given that the neutron data are more strongly affected by the iron content compared to X-rays (due to the large neutron coherent scattering length of $\mathrm{Fe}$ ), the conclusions drawn from the PDF data in this investigation is highly dependent on the type of radiation used in the analysis, with the presence of both amorphous mullite/alumina and amorphous iron-containing structural features being identified using X-rays and neutrons. If only one form of radiation was used, then an incomplete understanding of the bulk amorphous structure would have been obtained.

Except for HCFA, which exhibits a broad peak at $~ 2.55 \AA$, all the samples possess an atom-atom correlation at $\sim 2.35 \AA$, especially for GFA and IFA samples (Fig. 5b). This peak may be attributed to the $\mathrm{Ca}-\mathrm{O}$ correlation [36], and is seen to be more intense for the higher calcium content FA samples of GFA and IFA. The presence of this peak, which was not evident in X-ray PDFs, might be linked to the slightly higher scattering length density of Ca compared to other atoms, which allows it to be more visible in neutron data (e.g., $b_{C a}=4.70 v s b_{A l}=3.44$ ). Above an $r$ spacing of $2.5 \AA$, HCFA exhibits a different local atomic structure compared to the other samples (Fig. 5b). In fact, while the O-O and Si-Si correlations are clear for all the other FA samples, HCFA possesses a broad peak at $\sim 2.5$ to $2.7 \AA$ along with two distinct peaks at $\sim 3.7 \AA$ and $\sim 4.2 \AA$. As will be discussed in the next paragraph, these correlations are associated with the carbon phase(s) present in the sample. The broad correlation at $\sim 3.5 \AA$ in the AFA sample is attributed to Fe-Fe. This peak decreases in intensity for all the other types of FA and disappears in case of HCFA (which has the lowest amount of iron oxide, see Tab. 1 for details). A previous investigation on alkali ironcontaining aluminosilicate glasses [61] using neutron total scattering and empirical potential structure refinement modeling revealed that the glasses investigated, when containing iron in a range of coordination environments, is seen to possess a broad distribution of $\mathrm{Fe}-\mathrm{Fe}$ correlations between 2.6 and $3.8 \AA$.

To determine the type of carbon present in the HCFA sample, the carbon contributions were isolated by assuming that the remaining amorphous components in the HCFA possess similar atomic structural arrangements to the amorphous glassy structure for GFA. This enabled a subtraction procedure to be carried out, resulting in a difference PDF curve where only the atomatom contributions from the carbon phase(s) are present (Fig. 6). Comparison of the atom-atom correlations in Fig. 6 to a range of carbon-based phases reveals that the local atomic ordering of the carbon phase(s) in HCFA is very similar to graphite. Fig. 6 also displays the simulated neutron PDF of crystalline graphite with a spherical particle diameter of $\sim 10 \AA$ to mimic an amorphous/nanostructured phase of graphite. This particle diameter value was obtained by performing a real space refinement (PDFgui [48]), using the graphite crystal structure (ICSD \#76767 [68]). Other parameters were refined as follows: scale factor $=0.42$, atomic displacement parameters $u_{i}=0.0092 \AA^{2}$, lattice parameters $a=2.46 \AA$ and $c=6.94 \AA$. From Fig. 6 it is evident that the carbon present in HCFA is highly disordered, most likely due to disordered graphene sheets. However, the level of agreement achieved between the experimentally derived data and the simulated neutron PDF is quite good, especially given that the experimental dataset assumed that the non-carbon containing amorphous structure in HCFA was the same as that found in GFA, which is an approximation given the differences seen in the X-ray PDF data in Fig. 3b. Fig. 6 reveals that the $\mathrm{C}$-C correlation in the experimental data is located at $\sim 1.42 \AA$ [67] and the atom-atom correlations positioned at $\sim 3.70 \AA$ and $\sim 4.25 \AA$ are very similar to the local structural ordering found in graphite. Therefore, based on these results it is clear that the unburnt carbon in the high 
carbon content class F FA sample studied in this investigation possesses atomic structural ordering similar to disordered graphitic layers.

\subsection{Implications for the geopolymerization reaction}

The outcomes of this investigation, particularly the identification of amorphous mullite and amorphous iron oxide in some of the fly ashes, may correlate with the macroscopic properties of the resulting geopolymer pastes. Previous investigations have identified that the Si/Al ratio of the amorphous component of fly ashes is important for optimizing the formulation and mechanical properties of the alkali-activated fly ash pastes [69-71]. However, phase variability in the amorphous component, such as the presence of amorphous mullite and amorphous iron oxide, may also impact the development of the geopolymer gel phase(s) and corresponding macroscopic properties. Techniques are available to ascertain this information, such as in situ X-ray and neutron PDF analyses of the geopolymerization reaction for fly ash-based pastes. The results from these experiments would enable the identification of changes to the amorphous phases in the fly ashes, specifically if the amorphous mullite and amorphous iron oxide dissolve due to the geopolymerization process and are subsequently incorporated into the geopolymer gel.

\section{Conclusions}

In this investigation the atomic structure and associated variability in aluminosilicate glass chemistry for different types of class F FA, sourced from several coal power stations located around the world, was assessed. Pair distribution function (PDF) analysis, obtained by Fourier transformation of high-energy X-ray and neutron total scattering data, has been used to determine the average atomic ordering present in these FA samples, with the complementarity of X-rays and neutrons exploited to pinpoint the exact atom-atom correlations present in the samples. All FA samples showed a significant loss in atomic ordering above $\sim 5 \AA$ in both the $\mathrm{X}$-ray and neutron data, which is consistent with a mainly amorphous structure. The majority of the disagreement in local atomic ordering between samples is attributed to the presence of crystalline phases such as quartz, mullite and iron-components (maghemite, magnetite and hematite). After removal of crystalline phases, analysis of the short range atom-atom correlations revealed that the bulk glassy structure of the different FA sources are relatively similar, apart from those containing (i) amorphous mullite/alumina, (ii) high levels of iron in the glassy component and (iii) carbon. The presence of VI-coordinated aluminum (in the form of amorphous mullite or amorphous alumina) was unequivocally detected using X-rays, while neutrons, which are more sensitive to iron, showed the presence of amorphous iron (together with amorphous graphite in the high carbon-containing sample). The importance of combining the two methods is evident in this investigation, which has allowed for a deep and exhaustive understanding to be obtained on the local atomic ordering of class F FA, with future work to include analysis of the evolution of FA atomic structure during waste valorization processes, such as the alkali-activation reaction.

\section{Supplementary Material}

Tables containing the atom-atom correlation assignments and corresponding peak locations $(r$ values) for the FA samples before and after subtraction of the crystalline phases.

\section{Acknowledgments}

The neutron PDF experiments were performed on the NOMAD beamline at ORNL's Spallation Neutron Source (SNS), which is sponsored by the Scientific User Facilities Division, Office of Basic Energy Sciences, U.S. Department of Energy. X-ray PDF measurements were obtained on the 11-ID-B beamline at the Advanced Photon Source, a U.S. Department of Energy (DOE) Office of 
Science User Facility operated for the DOE Office of Science by Argonne National Laboratory under Contract No. DE-AC02-06CH11357. 11-ID-B data were collected as part of an APS Partner User Proposal granting access for NOMAD instrument studies. CEW was funded in part by the National Science Foundation under Grant No. 1362039. The authors would like to thank Katharine Page for X-ray and neutron PDF data measurement and reduction and Joerg C. Neuefeind for help using the IDL software for NOMAD instrument.

\section{References}

[1] Provis JL, van Deventer JSV. Alkali activated materials: State-of-the-art report. RILEM TC 224-AAM. Dorderecht: Springer/RILEM; 2014.

[2] Singh B, Ishwarya G, Gupta M, Bhattacharyya SK. Geopolymer concrete: A review of some recent developments. Constr Build Mater 2015;85:78-90.

[3] Provis JL, Palomo A, Shi C. Advances in understanding alkali-activated materials. Cem Concr Res 2015;78:110-25.

[4] Garcia-Lodeiro I, Palomo A, Fernández-Jiménez A, Macphee DE. Compatibility studies between N-A-S-H and C-A-S-H gels. Study in the ternary diagram $\mathrm{Na}_{2} \mathrm{O}-\mathrm{CaO}-\mathrm{Al}_{2} \mathrm{O}_{3}-\mathrm{SiO}_{2}-\mathrm{H}_{2} \mathrm{O}$. Cem Concr Res 2011;41:923-32.

[5] van Deventer JSJ, Provis JL, Duxson P, Brice DG. Chemical research and climate change as drivers in the commercial adoption of alkali activated materials. Waste Biomass Valorization 2010;1:145-55.

[6] Bignozzi MC, Manzi S, Natali ME, Richard WDA, van Riessen A. Room temperature alkali activation of fly-ash: The effect of $\mathrm{Na}_{2} \mathrm{O} / \mathrm{SiO}_{2}$ ratio. Constr Build Mater 2014;69:262-70.

[7] Gunasekara C, Law DW, Setunge S, Sanjayan JG. Zeta potential, gel formation and compressive strength of low calcium fly ash geopolymers. Constr Build Mater 2015;95:592-9.

[8] Palomo A, Grutzeck MW, Blanc MT. Alkali-activated fly ashes: A cement for the future. Cem Concr Res 1999;29:1323-9.

[9] Ryu GS, Lee YB, Koh KT, Chung YS. The mechanical properties of fly-ash based geopolymer concrete with alkaline activators. Constr Build Mater 2013;47:409-18.

[10] Fernández-Jiménez A, Palomo A. Characterization of fly ashes. Potential reactivity as alkaline cements. Fuel 2003;82:2259-65.

[11] Chancey RT, Stutzman P, Juenger MCG, Fowler DW. Comprehensive phase characterization of crystalline and amorphous phases of Class F fly ash. Cem Concr Res 2010;40:146-56.

[12] Aughenbaugh KL, Stutzman P, Juenger MCG. Assessment of the glassy phase reactivity in fly ash used for geopolymer cements. ASTM Special Technical Publication 2013;1566:11-20.

[13] Keyte L. What's wrong with Tarong? The importance of coal fly ash glass chemistry in inorganic polymer synthesis. Ph.D. thesis, Department of Chemical \& Biomolecular Engineering University of Melbourne, Australia. 2008.

[14] Oh JE, Jun Y, Jeong Y. Characterization of geopolymers from compositionally and physically different Class F fly ashes. Cem Concr Res 2014;50:16-26.

[15] Oh JE, Jun Y, Jeong Y, Monteiro PJM. The importance of network-modifying element content in fly ash as simple measure to predict its strength potential for alkali-activation. Cem Concr Res 2015;57:44-54.

[16] Nikolić V, Komljenović M, Baščarević Z, Marjanović N, Miladinović Z, Petrović R. The influence of fly ash characteristics and reaction conditions on strength and structure of geopolymers. Constr Build Mater 2015;94:361-70.

[17] Fernández-Jiménez A, Palomo A. Composition and microstructure of alkali activated fly ash binder: Effect of the activator. Cem Concr Res 2005;35:1984-92.

[18] Chi M. Effects of modulus ratio and dosage of alkali-activated solution of the properties and micro-structural characteristics of alkali-activated fly ash mortars. Constr Build Mater 2015;99:12836. 
[19] Criado M, Palomo A, Fernández-Jiménez A. Alkali activation of fly ashes. Part 1: effect of curing conditions on the carbonation of the reaction products. Fuel 2005;84:2048-54.

[20] Winnefeld F, Leemann A, Lucuk M, Svoboda P, Neuroth M. Assesment of phase formation in alkali activated low and high calcium fly ashes in building materials. Constr Build Mater 2010;24:1086-93.

[21] Bakharev T. Thermal behaviour of geopolymers prepared using class F fly ash and elevated temperature curing. Cem Concr Res 2006;36:1134-47.

[22] Pacheco-Torgal F, Abdollahnejad Z, Camões AF, Jamshidi M, Ding Y. Durability of alkaliactivated binders: A clear advantage over Portland cement or an unproven issue? Constr Build Mater 2012;30:400-5.

[23] Monticelli C, Criado M, Fajardo S, Bastidas JM, Abbottoni M, Balbo A. Corrosion behavior of a low Ni austenitic stainless steel in carbonated chloride-polluted alkali-activated fly ash mortars. Cem Concr Res 2014;55: 49-58.

[24] Monticelli C, Natali ME, Balbo A, Chiavari C, Zanotto F, Manzi S, et al. Corrosion behavior of steel in alkali activated fly ash mortars in the light of their microstructural, mechanical and chemical characterization. Cem Concr Res 2016;80:60-8.

[25] Blisset RS, Rowson NA. A review on the multi-component utilization of coal fly ash. Fuel 2012;97:1-23.

[26] Sow M, Hot J, Tribout C, Cyr M. Characterization of Spreader Stoker Coal Fly Ashes (SSCFA) for their use in cement-based applications. Fuel 2015;162:224-33.

[27] Yao TZ, Ji XS, Sarker PK, Tang JH, Ge LQ, Xia MS, et al. A comprehensive review on the applications of coal fly ash. Earth Sci Rev 2015;141:105-21.

[28] Bernal SA, Provis JL, Walkley B, San Nicolas R, Gehman JD, Brice DG, et al. Gel nanostructure in alkali-activated binders based on slag and fly ash, and effects of accelerated carbonation. Cem Concr Res 2013;53:127-44.

[29] Hemmings RT, Berry EE. Speciation in size and density fractionated fly ash. Materials Research Society Symposia Proceedings: V. 65. Fly Ash and Coal Conversion By-Products: Characterization, Utilization, and Disposal II. Boston, Massachusetts, USA: McCarthy, Glasser, Roy; 1985, p. 91-104.

[30] Arjuan P, Silbee MR, Roy DM. Quantitative determination of the crystalline and amorphous phases in low calcium fly ashes. Proceeding of the $10^{\text {th }}$ International Congress of the Chemistry of Cement. Gothenburg, Sweden; 1997, p. 2-6.

[31] McCusker LB, Von Dreele RB, Cox DE, Louer D, Scardi P. Rietveld refinement guidelines. J Appl Cryst 1998;32:36-50.

[32] Pektov V. Nanostructure by high-energy X-ray diffraction. Mater Today 2008;11(11):28-38.

[33] Provis JL, Hajimohammadi A, White CE, Bernal SA, Myers RJ, Winarski RP, et al. Nanostructural characterization of geopolymer by advanced beamline techniques. Cem Concr Comp 2013;36:56-64.

[34] Skinner LB, Chae AR, Benmore JC, Wenk HR, Monteiro PJM. Nanostructure of calcium silicate hydrates in cements. Phys Rev Let 2010;104:195502-4.

[35] White CE, Daemen LL, Hartl M, Page K. Intrinsic differences in atomic ordering of calcium (alumino) silicate hydrates in conventional and alkali-activated cements. Cem Concr Res 2015;67:66-73.

[36] Morandeau AE, White CE. In situ X-ray pair distribution function analysis of accelerated carbonation of a syntetic calcium-silicate hydrate gel. J Mater Chem A 2015;3:8597:605.

[37] Bell JL, Sarin P, Driemeyer PE, Heggerty RP, Chupas PJ, Kriven WM. X-ray pair distribution function analysis of metakaolin-based, $\mathrm{KAlSi}_{2} \mathrm{O}_{6} \cdot 5.5 \mathrm{H}_{2} \mathrm{O}$ inorganic polymer (geopolymer). J Mater Chem 2008;18:5974-81.

[38] Provis JL, Duxson P, van Deventer JSJ, Luckey GC. The role of mathematical modeling and gel chemistry in advancing geopolymer technology. Chem Eng Res Des 2005;83:853-60. 
[39] Meral C, Benmore CJ, Monteiro PJM. The study of disorder and nanocrystallinity in C-S-H, supplementary cementitious materials and geopolymers using pair distribution function analysis. Cem Concr Res 2011;41:696-710.

[40] White CE, Page K, Henson NJ, Provis JL. In situ synchrotron X-ray pair distribution function analysis of the early stages of gel formation in metakaolin-based geopolymers. Appl Clay Sci 2013;73:17-25.

[41] White CE, Provis JL, Poffen T, van Deventer JSJ. The effect of temperature on the local structure of metakaolin-based geopolymer binder: a neutron pair distribution function investigation. J Amer Cer Soc 2010;93:3486-92.

[42] White CE, Provis JL, Llobet A, Poffen T, van Deventer JSJ. Evolution of local structure in geopolymer gels: an in-situ neutron pair distribution function analysis. J Amer Cer Soc 2011;94:3532-9.

[43] Morandeau AE, White CE. Role of magnesium-stabilized amorphous calcium carbonate in mitigating the extent of carbonation in alkali-activated slag. Chem Mater 2015;27(19):6625-34.

[44] Oh JE, Moon J, Mancio M, Clark SM, Manteiro PJM. Bulk modulus of basic sodalite $\mathrm{Na}_{8}\left[\mathrm{AlSiO}_{4}\right]_{6}(\mathrm{OH})_{2} \cdot 2 \mathrm{H}_{2} \mathrm{O}$, a possible zeolite precursor in coal-fly-ash-based geopolymers. Cem Concr Res 2011;41:107-12.

[45] Chupas PJ, Chapman KW, Lee PL. Applications of an amorphous silicon-based area detector for high-resolution, high-sensitivity and fast time-resolved pair distribution function measurements. J Appl Cryst 2007;40(3):463-70.

[46] Hammersley AP, Svensson SO, Hanfield M, Fitch AM, Hausermann D. Two-Dimensional Detector Software: From Real Detector to Idealised Image or Two-Theta Scan. High Pressure Res 1996;14:235-48.

[47] Qui X, Thompson JW, Billinge SJL. PDFgetX2: a GUI-driven program to obtain the pair distribution function from X-ray powder diffraction data. J Appl Cryst 2004;37(4):678.

[48] Farrow CL, Juhas P, Liu JW, Bryndin D, Bozin ES, Bloch J, et al. PDFfit2 and PDFgui: computer programs for studying nanostructure in crystals. J Phys Condens Mat 2007;19:335219.

[49] Neuefeind J, Feygenson M, Carruth J, Hoffmann R, Chipley KK. The Nanoscale Ordered MAterials Diffractometer NOMAD at the Spallation Neutron Source SNS. Nucl Instrum Methods Phys Res B 2012;287:68-75.

[50] Gualtieri AF. Accuracy of XRPD QPA using the combined Rietveld-RIR method. J of Appl Cryst 2000;33:267-78.

[51] Durovič S. Refinement of the crystal structure of mullite. Chem Zvesti 1969;23:113-128.

[52] Shmakov AN, Kryukova GN, Tsybulya SV, Chuvilin AL, Solovyeva LP. Vacancy ordering in $\gamma-\mathrm{Fe}_{2} \mathrm{O}_{3}$ : Synchrotron X-ray powder diffraction and high-resolution electron microscopy studies. J Appl Cryst 1995;28:141-5.

[53] Iizumi M, Koetzle TF, Shirane G, Chikazumi S, Matsui M, Todo S. Structure of magnetite $\mathrm{Fe}_{3} \mathrm{O}_{4}$ below the Verwey transition temperature. Acta Cryst B 1982;38:2121-33.

[54] van Hoang V. Composition dependence of static and dynamic heterogenities in simulated liquid aluminum silicates. Phis Rev B 2007;75:174-202.

[55] Winkler A, Horbach J, Kob W, Binder K. Structure and diffusion in amorphous aluminum silicate: a molecular dynamics computer simulation. J Chem Phys 2004;120:384-93.

[56] Anderson PR, Swartz WE. X-ray photoelectron spectroscopy of some aluminosilicates. Inorg Chem 1974;13(9);2293-4.

[57] Petkov V, Billinge SJL, Shastri SD, Himmel B. Polyhedral units and network connectivity in calcium aluminosilicate glasses from high-energy X-ray diffraction. Phys Rev Lett 2000;85(16);3436-9.

[58] Cimasu AC, Michel FM, Tcaciuc AP, Brown Jr GE. Properties of impurity-bearing ferrihydrite III. Effects of Si on the structure of 2-line ferrihydrite. Geochim Cosmochim Acta 2014;1333:16885. 
[59] Babay S, Mhiri T, Toumi M. Synthesis. Structural and spectroscopic characterizations of maghemite $\gamma-\mathrm{Fe}_{2} \mathrm{O}_{3}$ prepared by one-step coprecipitation route. J Mol Struct 2015;1085:286-93.

[60] King G, Ramezanipour F, Llobet A, Greedan JE. Local structures of $\mathrm{Sr}_{2} \mathrm{FeMnO}_{5+\mathrm{y}}(\mathrm{Y}=0,0.5)$ and $\mathrm{Sr}_{2} \mathrm{Fe}_{1.5} \mathrm{Cr}_{0.5} \mathrm{O}_{5}$ from reverse Monte Carlo modeling of pair distribution function data and implications for magnetic order. J Solid State Chem 2013;98:407-15.

[61] Weigel C, Cormier L, Calas G, Galoisy L, Bowron DT. Intermediate-range order in the silicate network glasses $\mathrm{NaFe}_{\mathrm{x}} \mathrm{Al}_{1}-\mathrm{xSi}_{2} \mathrm{O}_{6}(\mathrm{x}=0,0.5,0.8,1)$ : A neutron diffraction and empirical potential structure refinement modeling investigation. Phys Rev B 2008;78(6):064202.

[62] Fisher RX, Schneider H, Schmücker M. Crystal structure of Al-rich mullite. Am Miner 1994;79:983-90.

[63] Loewenstein $\mathrm{W}$. The distribution of aluminum in the tetrahedra of silicates and aluminates. Am Mineral 1954;39(1-2):92-6.

[64] Lloyd R, Provis JL, van Deventer JSJ. Microscopy and microanalysis of inorganic polymer cements.1: remnant fly ash particles. J Mater Sci 2009;44:608-19.

[65] Jacques SDM, Di Michiel M, Kimber SAJ, Yang X, Cernik RJ, Beale AM, et al. Pair distribution function computed tomography. Nat Commun 2013;4:2536.

[66] White CE. Effect of temperature on the atomic structure of synthetic calcium-silicate-detyerate gels: A neutron pair distribution function investigation. Cem Concr Res 2015;79:93-100.

[67] Brown TE, LeMay H, Bursten H. Chemistry The Central Science. Upper Saddle River, NJ: Simon \& Schuster; 1997 (227), p. 412-3.

[68] Trucano P, Chen R. Structure of graphite by neutron diffraction. Nature 1975;258:136-7.

[69] Williams RP, van Riessen A. Determination of the reactive component of fly ashes for geopolymer production using XRF and XRD. Fuel 2010;89:3683-92.

[70] van Riessen A, Chen-Tan N. Beneficiation of Collie fly ash for synthesis of geopolymer: Part 1 - Beneficiation. Fuel 2013;106:569-75.

[71] van Riessen A, Chen-Tan N. Beneficiation of Collie fly ash for synthesis of geopolymer: Part 2 - Geopolymers. Fuel 2013;111:829-35. 
Table 1. Principal oxides composition of FA and LOI (Loss On Ignition).

\begin{tabular}{cccccccccc}
\hline \multirow{2}{*}{$\begin{array}{c}\text { Type } \\
\text { of FA }\end{array}$} & \multicolumn{7}{c}{ Components (wt. \% as oxides) } \\
\cline { 2 - 10 } & $\mathrm{SiO}_{2}$ & $\mathrm{Al}_{2} \mathrm{O}_{3}$ & $\mathrm{Fe}_{2} \mathrm{O}_{3}$ & $\mathrm{CaO}$ & $\mathrm{MgO}$ & $\mathrm{SO}_{3}$ & $\mathrm{Na}_{2} \mathrm{O}$ & $\mathrm{K}_{2} \mathrm{O}$ & LOI \\
\hline IFA & 49.37 & 29.23 & 2.71 & 6.63 & 1.05 & 0.33 & 0.05 & 0.60 & 3.28 \\
\hline AFA & 51.85 & 26.60 & 13.00 & 1.72 & 1.38 & 0.30 & 0.42 & 0.90 & 0.31 \\
\hline GFA & 53.13 & 22.07 & 8.04 & 6.04 & 2.37 & 0.60 & 0.91 & 2.16 & 2.39 \\
\hline AMFA & 41.43 & 21.64 & 12.66 & 3.24 & 0.99 & 0.30 & 0.38 & 1.78 & 3.09 \\
\hline HCFA & 58.67 & 25.95 & 5.32 & 1.32 & $/$ & 0.19 & $/$ & $/$ & 11.37 \\
\hline
\end{tabular}


Table 2. Principal atoms (molar \%).

\begin{tabular}{ccccccc}
\hline \multirow{2}{*}{$\begin{array}{c}\text { Type } \\
\text { of FA }\end{array}$} & $\mathrm{Si}$ & $\mathrm{Al}$ & $\mathrm{Fe}$ & $\mathrm{Ca}$ & $\mathrm{Si} / \mathrm{Al}$ & $\begin{array}{c}\mathrm{Al}_{2} \mathrm{O}_{3} / \\
\mathrm{SiO}_{2}\end{array}$ \\
\cline { 2 - 7 } & & & & & & \\
\hline IFA & 53.11 & 37.06 & 2.19 & 7.64 & 1.43 & 0.35 \\
\hline AFA & 54.68 & 33.06 & 10.32 & 1.94 & 1.65 & 0.30 \\
\hline GFA & 57.96 & 28.38 & 6.60 & 7.06 & 2.04 & 0.24 \\
\hline AMFA & 51.83 & 31.91 & 11.92 & 4.34 & 1.62 & 0.31 \\
\hline HCFA & 61.97 & 31.31 & 4.23 & 1.49 & 1.92 & 0.26 \\
\hline
\end{tabular}


Table 3. Scale factors after refinement of the principal crystalline components, obtained by refinement of the X-ray/neutron PDF data.

\begin{tabular}{|c|c|c|c|c|c|}
\hline \multicolumn{2}{|c|}{ Type of FA } & Quartz & Mullite & Maghemite & Magnetite \\
\hline \multirow{2}{*}{ IFA } & X-ray & 0.13 & 0.16 & 0.06 & $/$ \\
\cline { 2 - 6 } & Neutron & 0.08 & 0.06 & 0.02 & $/$ \\
\hline \multirow{2}{*}{ AFA } & X-ray & 0.19 & 0.23 & $/$ & 0.14 \\
\cline { 2 - 6 } & Neutron & 0.12 & 0.06 & $/$ & 0.05 \\
\hline \multirow{3}{*}{ GFA } & X-ray & 0.11 & 0.14 & 0.05 & $/$ \\
\cline { 2 - 7 } & Neutron & 0.06 & 0.04 & 0.02 & $/$ \\
\hline \multirow{2}{*}{ AMFA } & X-ray & 0.08 & 0.18 & 0.12 & $/$ \\
\cline { 2 - 7 } & Neutron & 0.04 & 0.04 & 0.03 & $/$ \\
\hline \multirow{2}{*}{ HCFA } & X-ray & 0.13 & 0.15 & 0.02 & $/$ \\
\cline { 2 - 7 } & Neutron & 0.10 & 0.05 & 0.02 & $/$ \\
\hline
\end{tabular}




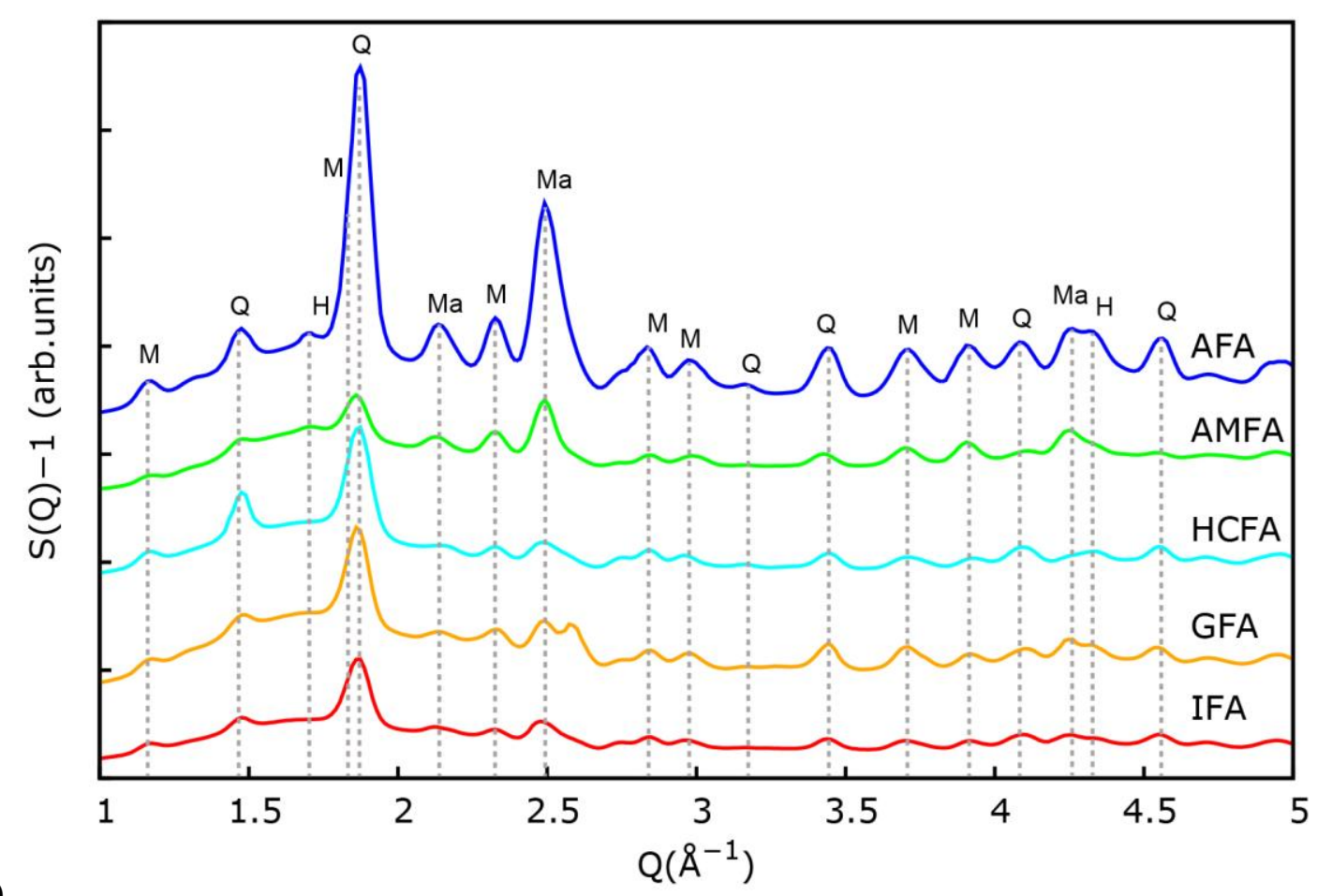

a)

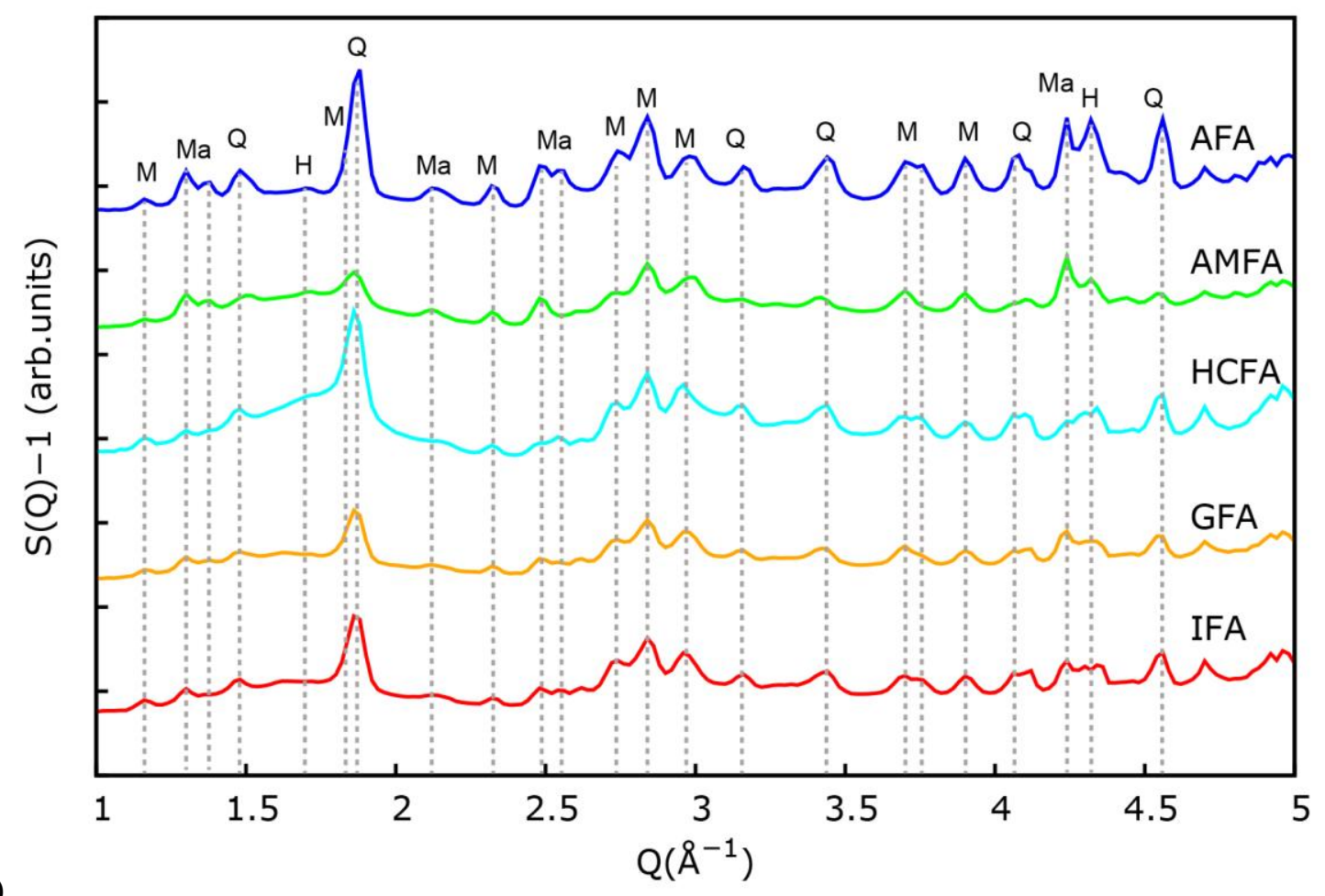

b)

Figure 1. Synchrotron-based X-ray (a) and neutron (b) diffraction patterns of the analyzed FA (Q=quartz (PDF \#00-001-0649); M=mullite (PDF \#00-001-0613) Ma=maghemite/magnetite (PDF \#00-013-0458/\#00-019-0629); H=hematite (PDF \#00-002-0915). 


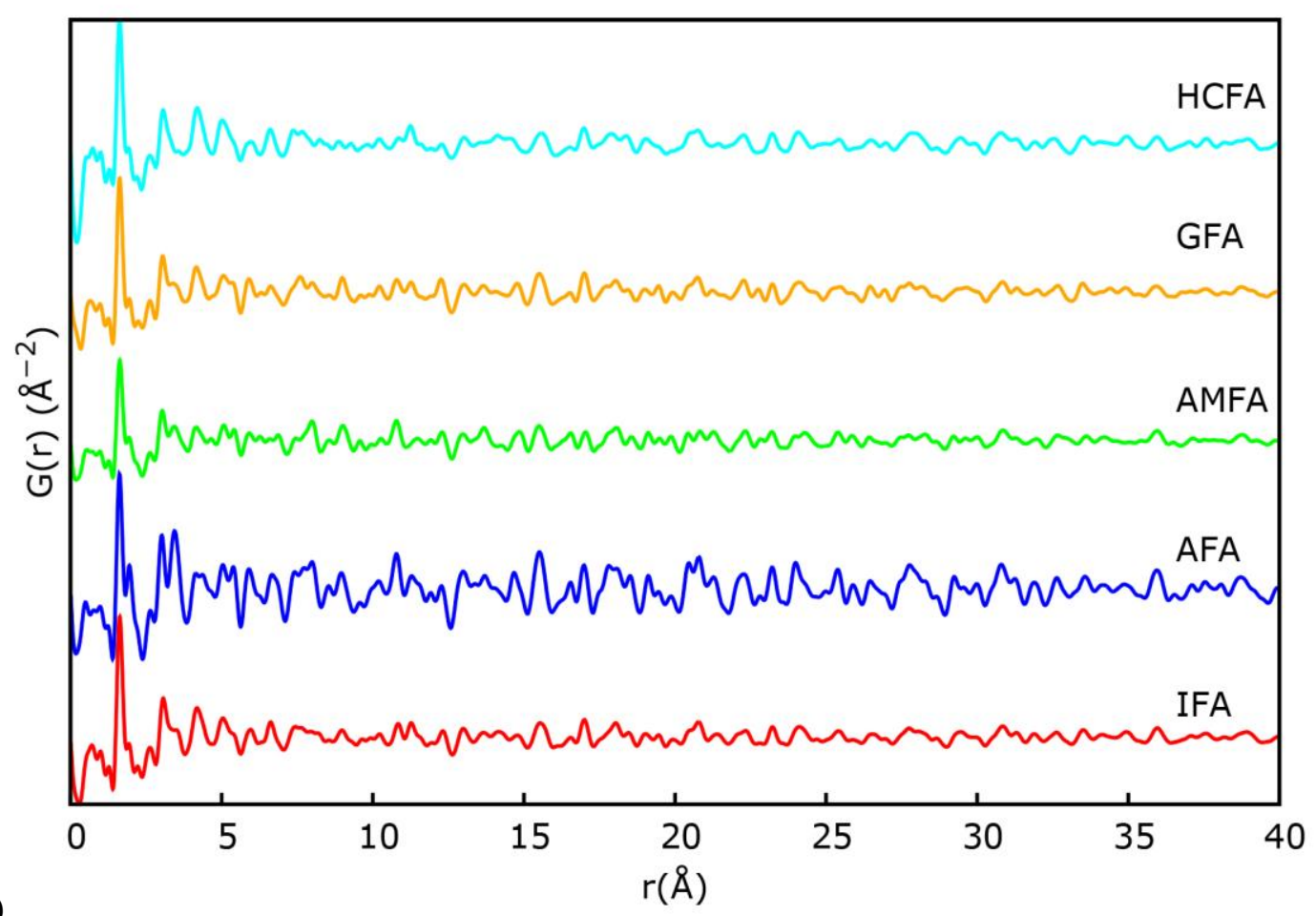

a)

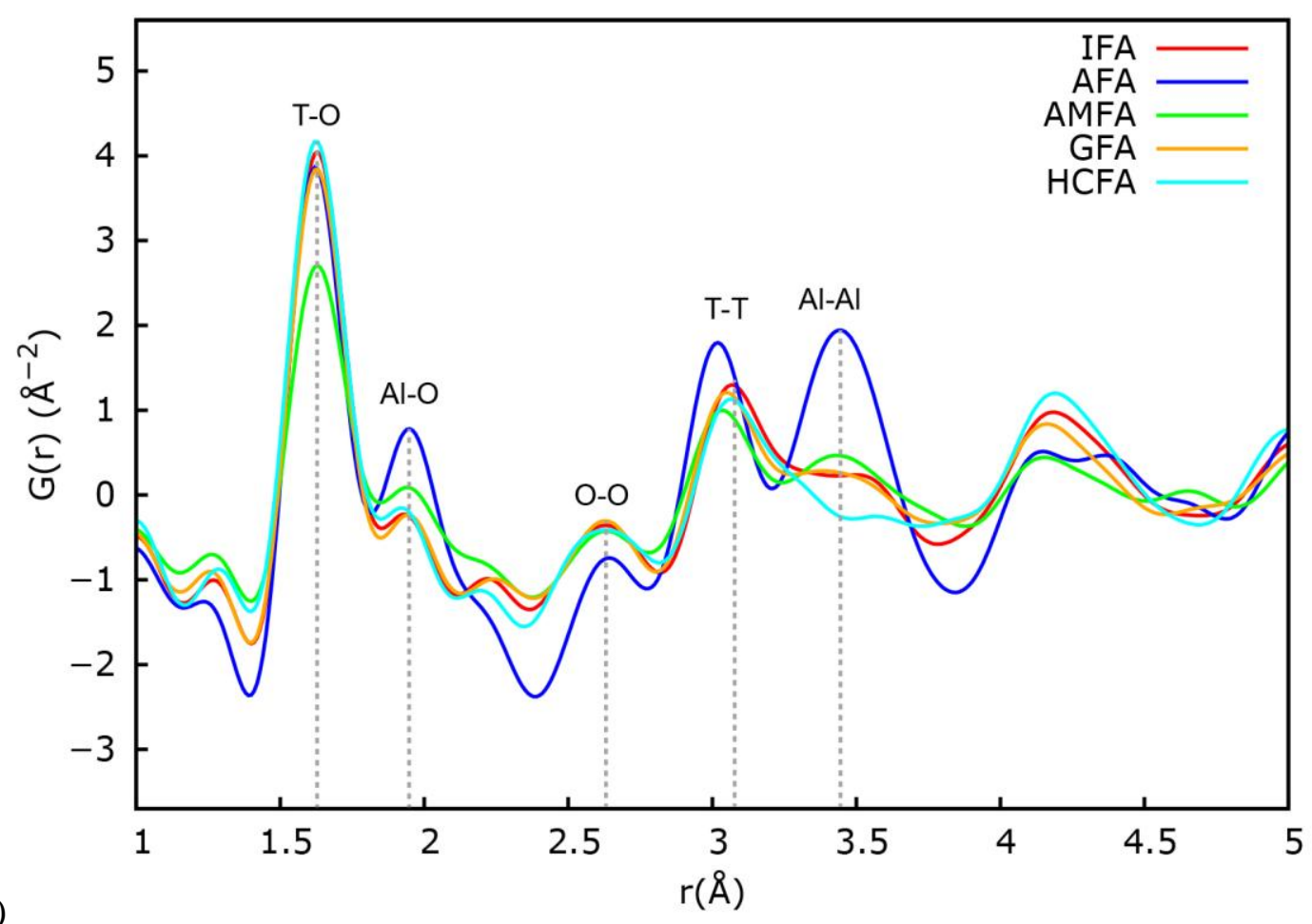

Figure 2. X-ray PDFs of all the analyzed FA; (a) up to $40 \AA$, and (b) over the region $1 \leq \mathrm{r} \leq 5 \AA$. 


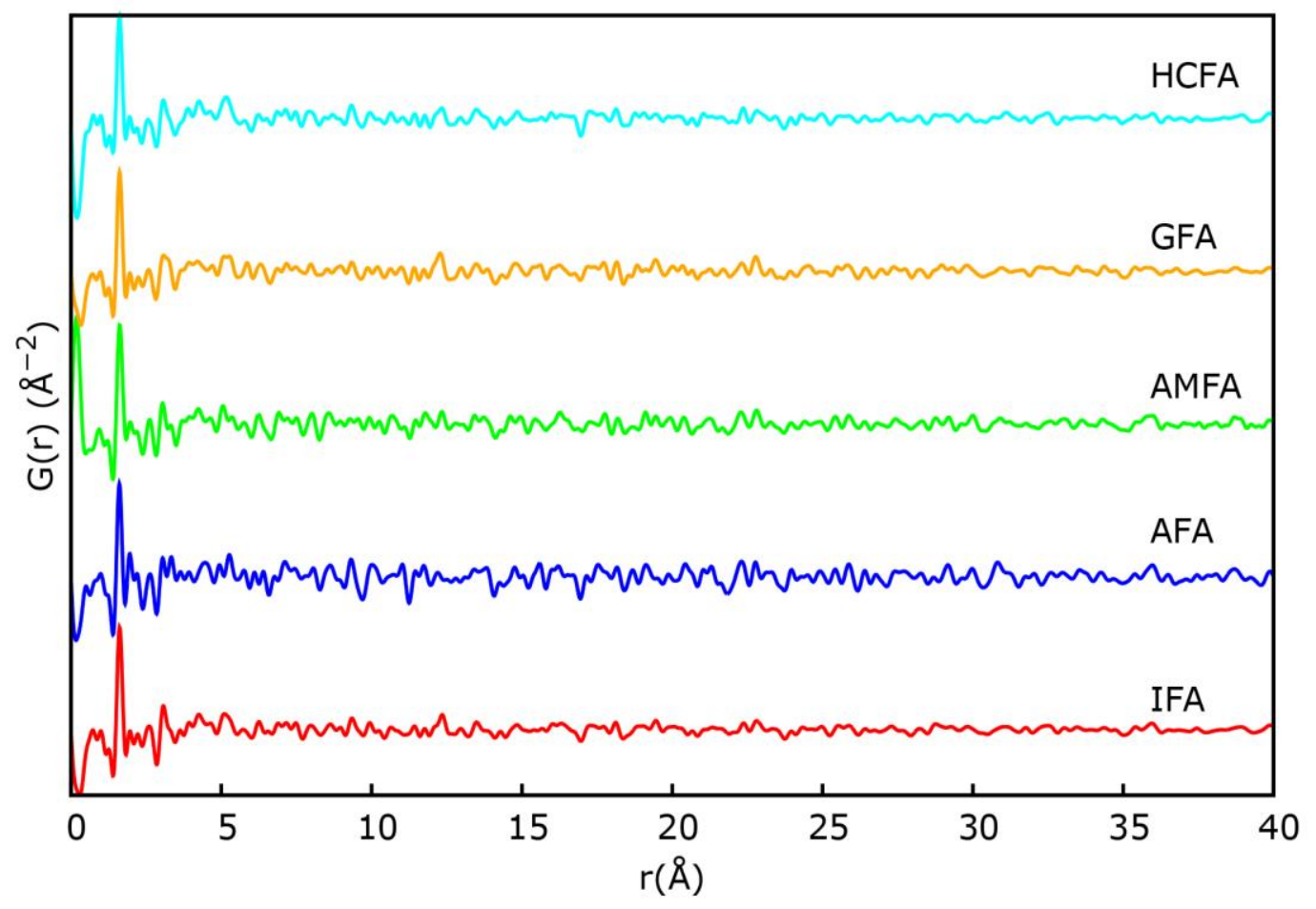

a)

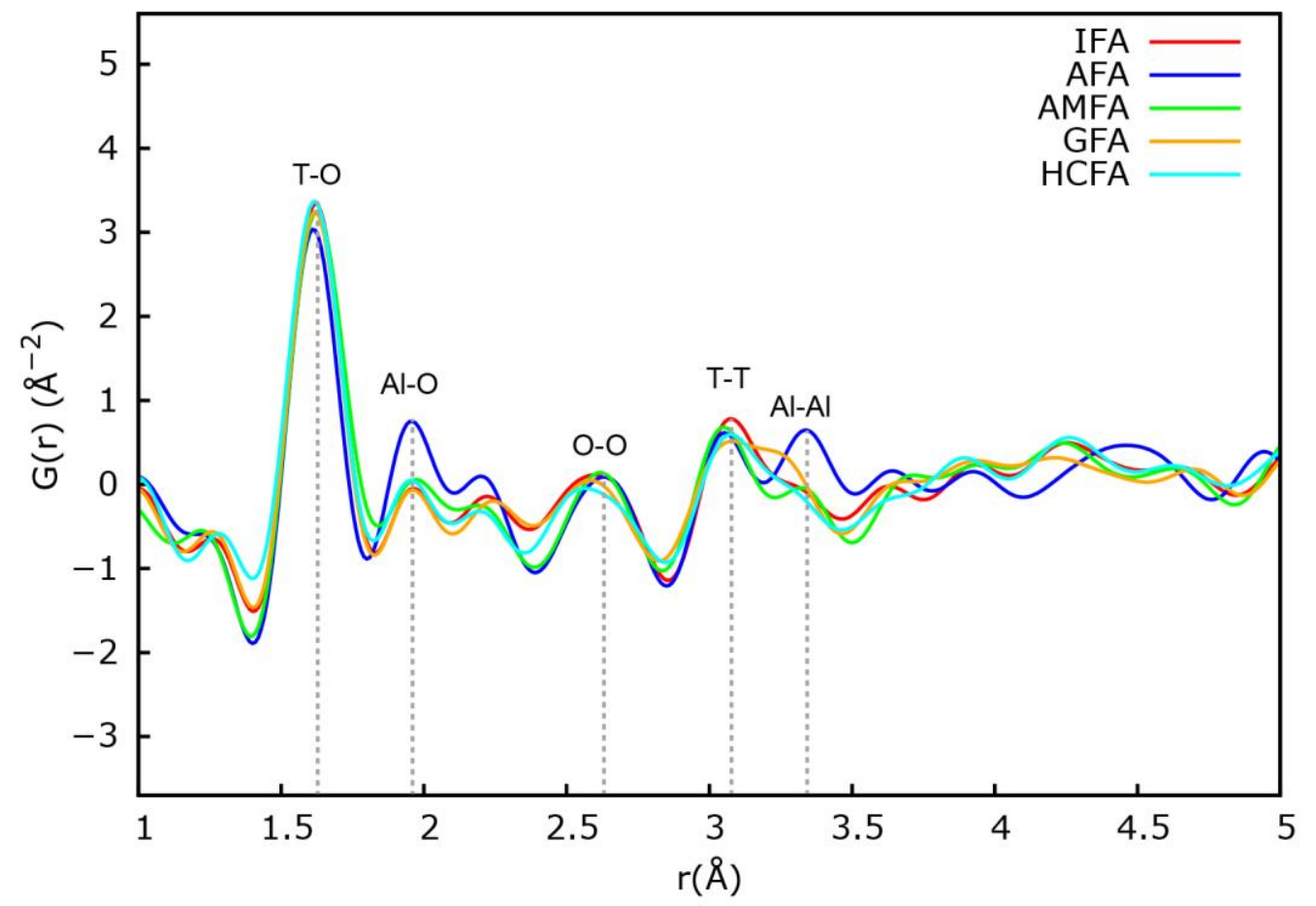

Figure 3. X-ray PDFs of all the analyzed FA after subtraction of the crystalline phases; (a) up to 40 $\AA$, and (b) over the region $1 \leq \mathrm{r} \leq 5 \AA$. 


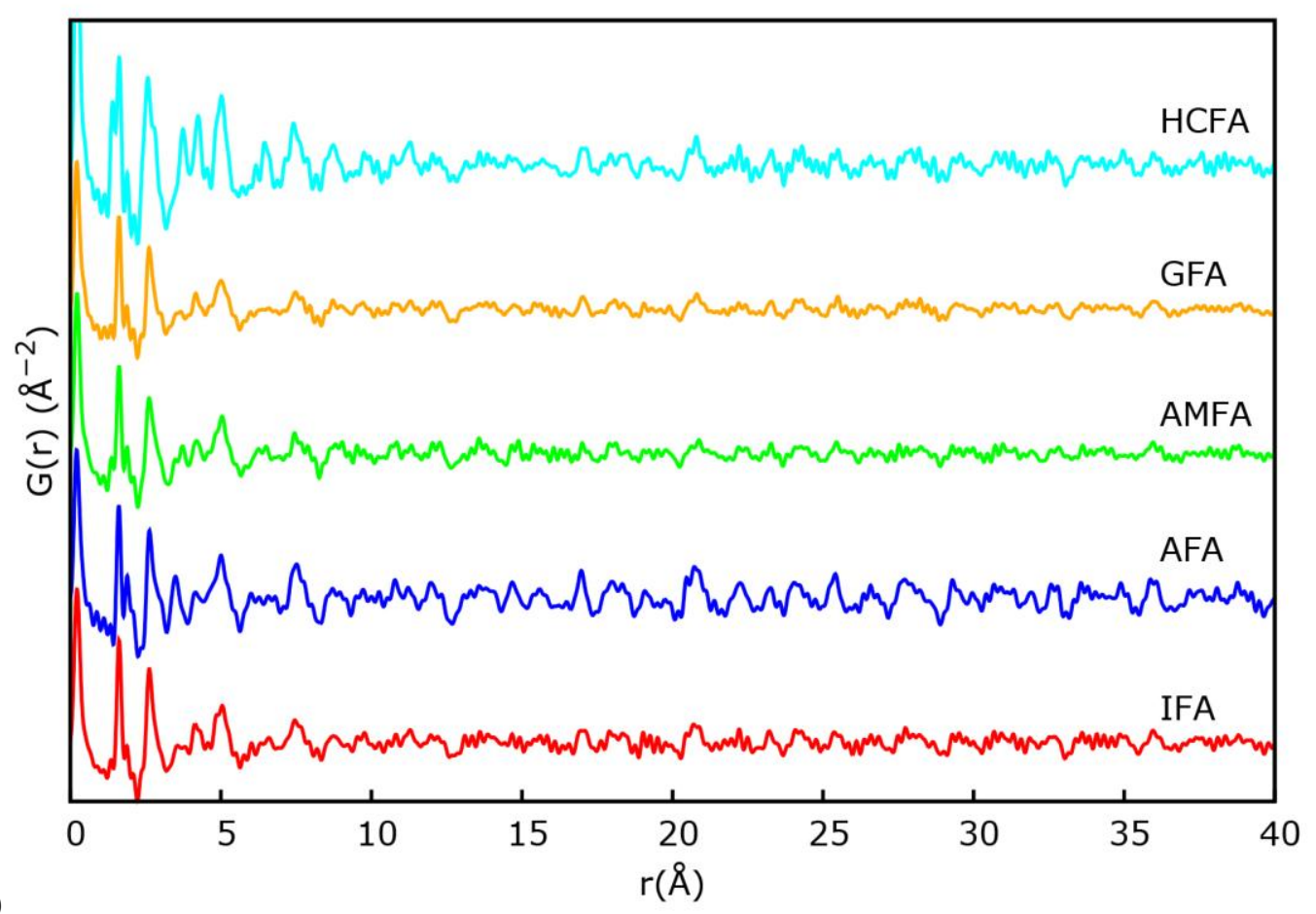

a)

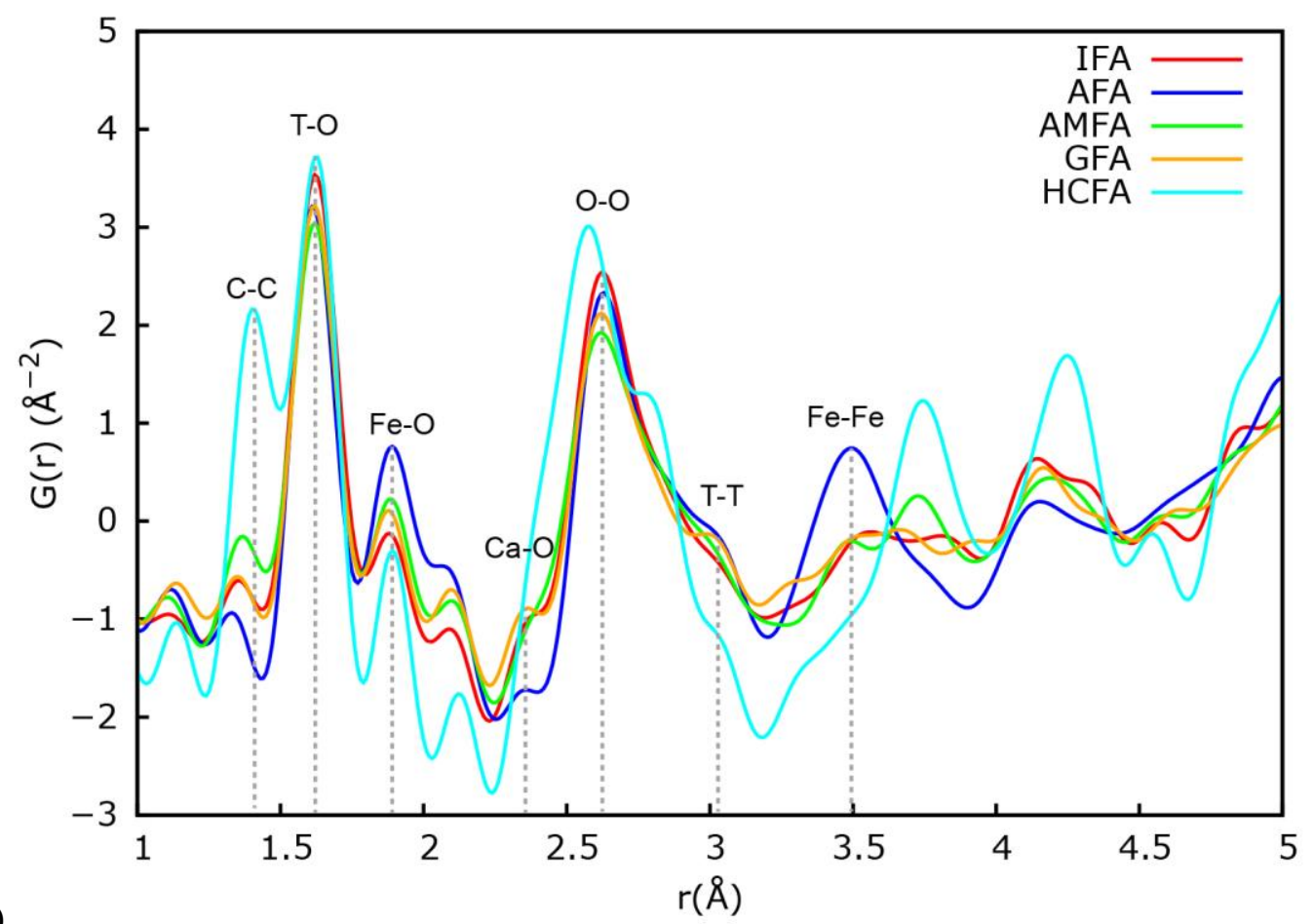

Figure 4. Neutron PDFs of all the analyzed FA; (a) up to $40 \AA$, and (b) over the region $1 \leq \mathrm{r} \leq 5 \AA$. 


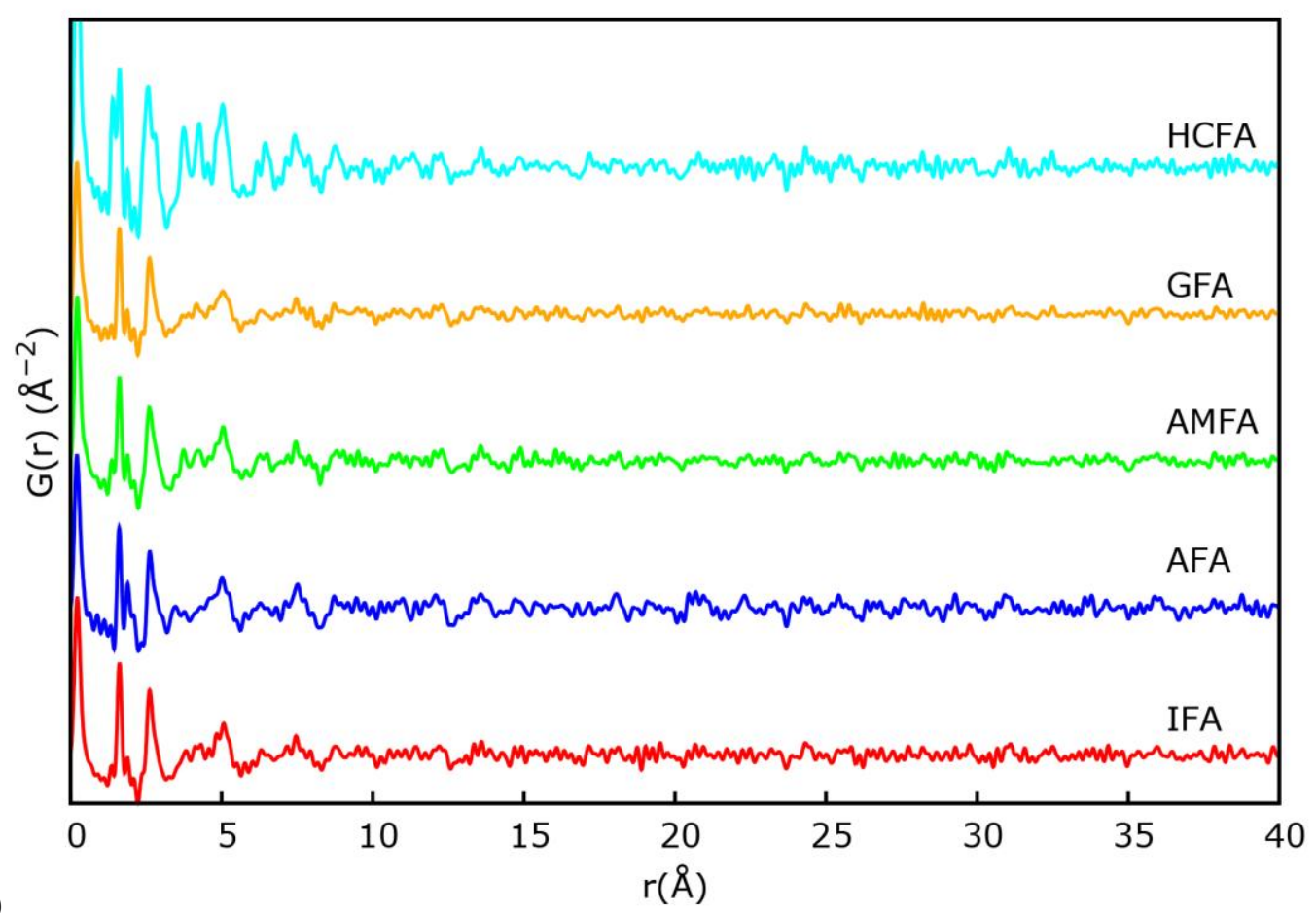

a)

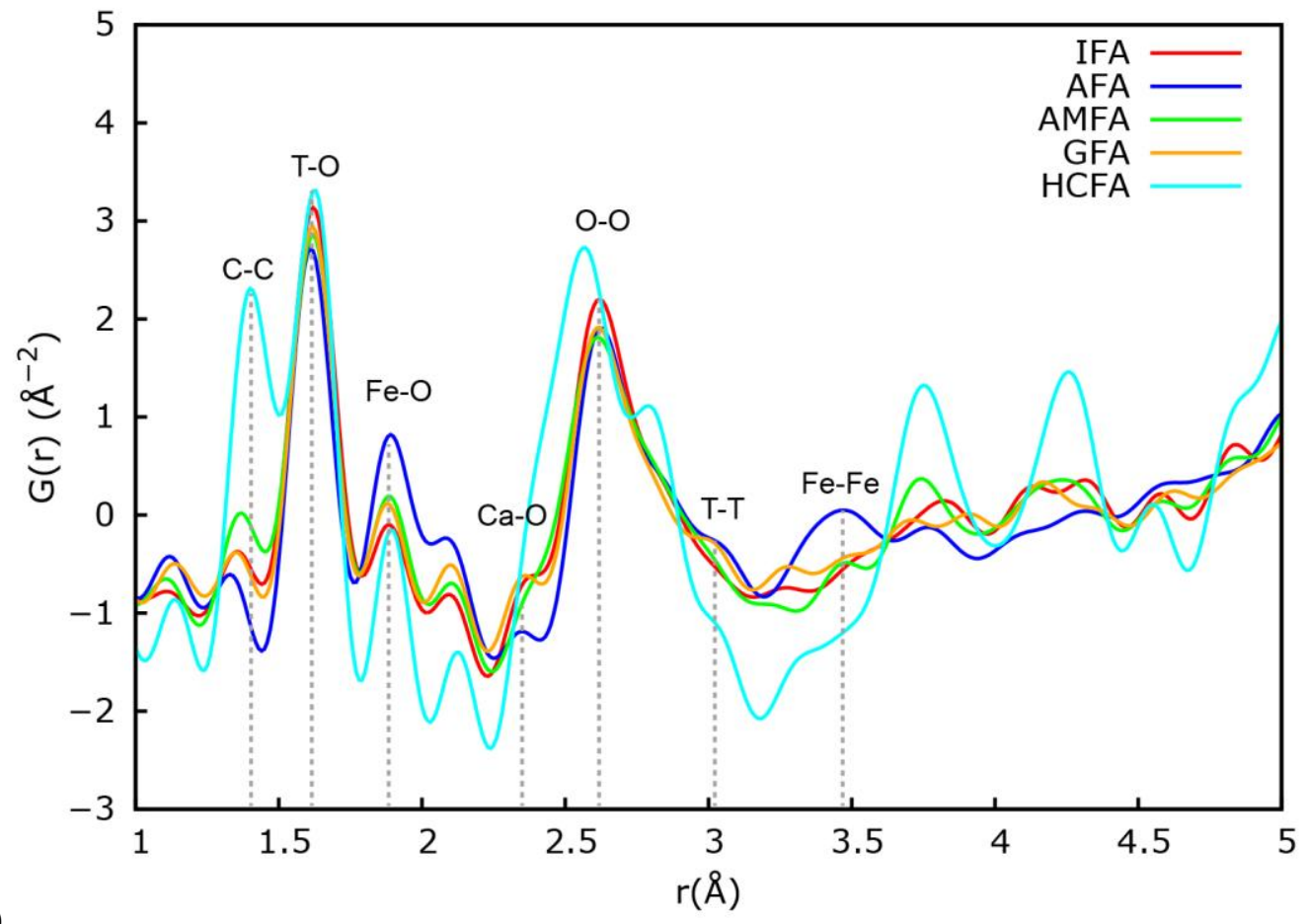

b)

Figure 5. Neutron PDFs of all the analyzed FA after crystalline phases subtraction; (a) up to $40 \AA$, and (b) over the region $1 \leq \mathrm{r} \leq 5 \AA$. 


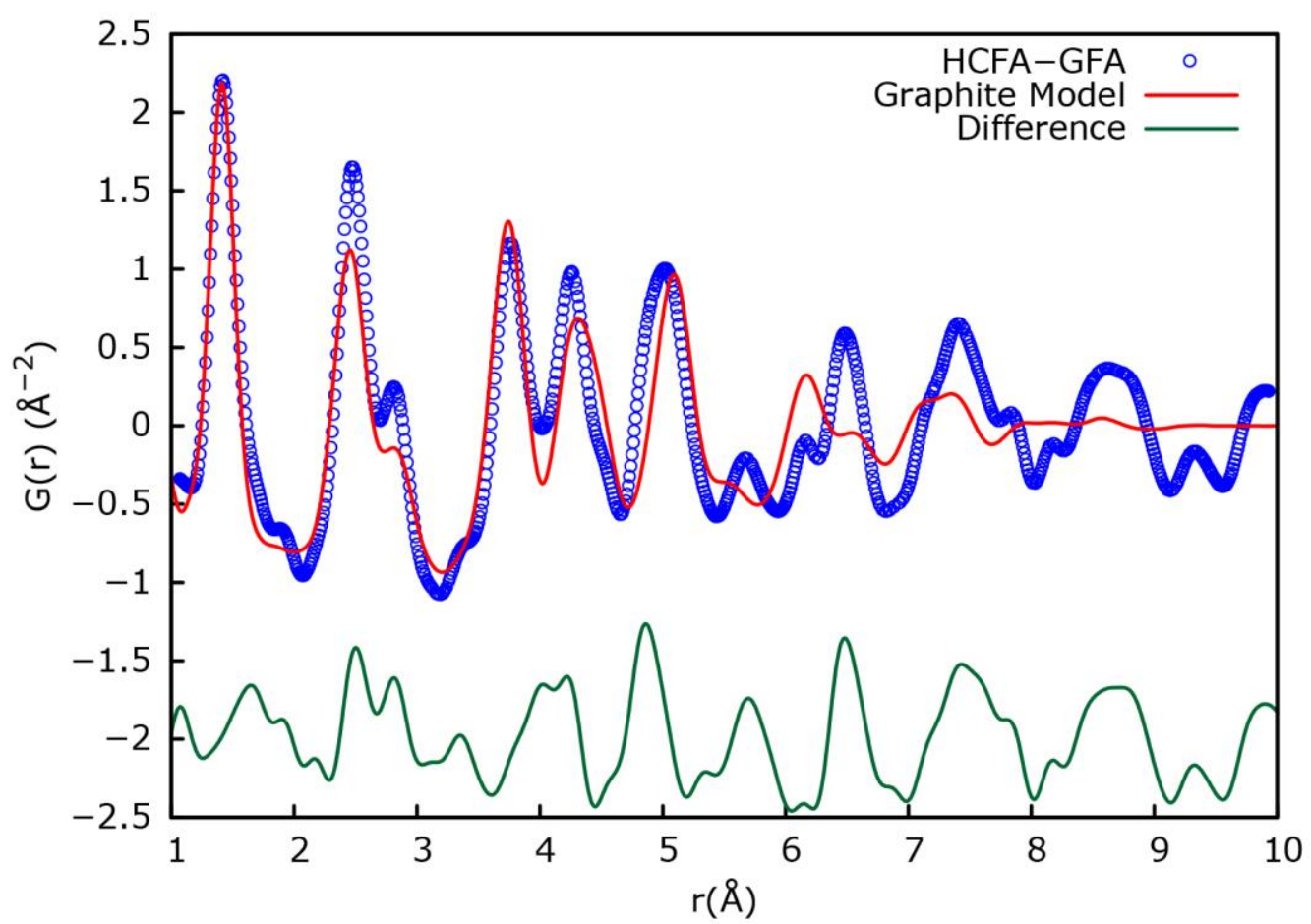

Figure 6. Neutron PDF for HCFA-GFA data (blue curve), the simulated graphite crystalline structure (red line [68]) and their difference (green line) over the region $1 \leq \mathrm{r} \leq 10 \AA$. 